\title{
Quando a ciência é ídolo: um comentário crítico sobre a psicologia moral nietzschiana de Leiter
}

\author{
Jonas Backendorf*
}

Resumo: A finalidade deste artigo é bastante pontual e específica: evidenciar os problemas do tratamento acrítico dado à psicologia por Brian Leiter em seu recente Moral Psychology with Nietzsche (2019). O autor inclui, sem se empenhar em qualquer discussão metodológica, a psicologia no rol do que chama de "ciências bem-sucedidas", tomadas como i) certificadoras do m-naturalismo nietzschiano; ii) dotadas de primazia sobre a própria filosofia na determinação do que é um "raciocínio filosófico" significativo; iii) fornecedoras de um amplo e inconteste corpo de evidências de que a psicologia moral de Nietzsche "está certa" em relação a teses profundamente complexas. Minha exposição consiste em mapear a construção conceitual desse m-naturalismo, e, posteriormente, evidenciar que não há, na psicologia empírica contemporânea, nada próximo da caracterização pretendida por Leiter.

Palavras-chave: Leiter, Nietzsche, naturalismo, ciência, psicologia.

\footnotetext{
* Doutorando pela Universidade Federal de Santa Maria, Santa Maria, RS, Brasil.

ORCID https://orcid.org/0000-0003-3951-3164

Correio eletrônico: jonasb90@hotmail.com
} 
Backendorf, J.

Em que situações desnaturadas, artificiais, e, em todo caso, indignas, há de cair, em uma época que sofre de cultura geral, a mais verdadeira de todas as ciências, a deusa nua e sincera, a filosofia?!? (HL/Co. Ext. II, 5)

\section{Introdução}

A discussão psicológica ocupa um espaço central no pensamento de Nietzsche. Além de caracterizar a si mesmo como o primeiro verdadeiro psicólogo, o autor definiu a psicologia como a senhora de todas as ciências, aquela que conduz aos problemas fundamentais e para a qual todas as outras devem estar a serviço (EH/EH, Por que sou um destino, 6; JGB/BM, 23). Mas "psicologia" nos termos de Nietzsche guarda pouca semelhança com "psicologia" nos nossos termos atuais: dado o modo profundamente crítico e idiossincrático como o autor trata a questão ${ }^{1}$, temos diversos motivos para acreditar que ele recusaria fortemente qualquer aproximação com os métodos predominantes na psicologia acadêmica dos nossos dias. ${ }^{2}$ Em seu recente Moral Psychology with Nietzsche (2019), Brian Leiter fornece uma imagem distinta do filosofar nietzschiano.

O autor apresenta Nietzsche como "naturalista humeano", em oposição, segundo Leiter, a leituras errôneas (qualificadas como ideologicamente motivadas, p. 10) de autores como Heidegger, Derrida e Rorty, leituras que, dada a sua força, teriam atravancado o desenvolvimento de uma psicologia acadêmica mais fortemente

1 cf. Giacoia Jr. 2001, p. 11.

2 Giacoia Jr. fornece uma imagem geral do que a amplitude metodológica do pensamento de Nietzsche significa: "O psicólogo Nietzsche desenvolve uma noção radicalmente interdisciplinar de sua disciplina, que exige o concurso de elementos provenientes da filosofia, da filologia, da fisiologia, da história, da antropologia cultural, da etnologia, da semiótica, da linguística, da literatura, entre outras, para fazer do pensamento uma escola da suspeita permanente, que parte do sentido manifesto das produções culturais em busca do sentido oculto em suas múltiplas condições de surgimento, desenvolvimento e transformação" (Giacoia Jr., 2001, p. 11).

190 | Cad. Nietzsche, Guarulhos/Porto Seguro, v.40, n.3, p. 189-213, setembro/dezembro, 2019. 
Quando a ciência é ídolo: um comentário crítico sobre a psicologia...

nietzschiana (p. 10). A caracterização do que seria o naturalismo de Nietzsche traz o aspecto problemático dessa leitura: Nietzsche seria um "naturalista de método" ("m-naturalista", p. 2) - o que pode, em princípio, ser facilmente aceito. O problema aparece na definição e, principalmente, no uso pessoal que faz Leiter desse $m$-naturalismo: ser um m-naturalista como Nietzsche significaria, segundo Leiter, "exigir continuidade com os métodos das ciências bem-sucedidas" (Leiter, 2019, p. 2).

Conforme procuro evidenciar, o que há de particularmente problemático em sua abordagem é o fato de que o autor toma como um dado, alheio à necessidade de discussão crítica, que as ciências, em especial a psicologia, são por si dotadas de autoridade e legitimidade (como representantes das posturas naturalistas), e, principalmente, de uma unidade e um consenso metodológicos que aparentemente permanecem inalterados ao longo tempo. $\mathrm{O}$ estatuto um tanto nebuloso disso fica claro, por exemplo, quando Leiter, contra a própria sabedoria filosófica, subordinando esta às "ciências que funcionam", sugere que "os naturalistas negam que exista algo chamado "raciocínio filosófico’ que se afaste dos tipos de raciocínio que funcionam nas várias ciências naturais e humanas" (p. 106). ${ }^{3}$ Infelizmente, ao longo de todo o livro, o autor não nos fornece qualquer consideração sobre o que seria uma ciência humana "bem-sucedida" ou que "funciona" (mesmo no capítulo em que se detém especificamente a apresentar estudos empíricos, não há uma palavra sobre o assunto), resumindo-se à postura alarmista e sobretudo maniqueísta segundo a qual a posição de crítica às "ciências que funcionam” (uma vez que são avalistas do naturalismo que Leiter atribui a Nietzsche) representa uma abertura

3 Cox nos apresenta uma leitura em direta oposição à de Leiter: "Nietzsche insiste que um 'naturalismo' completo não pode ser um cientificismo; isto é, não pode aceitar a visão quineana de que 'o mundo é como a ciência natural diz que é' e que 'o naturalismo está pautado apenas na ciência natural [...] para uma explicação do que existe e de como existe'. A genealogia de Nietzsche do pensamento europeu revela uma teologia residual na alegação do projeto científico moderno de descrever a maneira como o mundo realmente é" (Cox, 1999, pp. 5-6). A tradução desta e de todas as demais citações em língua estrangeira deste texto são minhas.

Cad. Nietzsche, Guarulhos/Porto Seguro, v.40, n.3, p. 189-213, setembro/dezembro, 2019. 191 
Backendorf, J.

a toda sorte de obscurantismo e arbitrariedade ( $c f$. p. 106), como se as nossas únicas opções fossem, nas palavras de Leiter, por um lado, o "método científico" e, por outro, o que "o livro sagrado diz ou o que o santo líder declara" (p. 111). Não bastasse isso, o autor, de uma maneira realmente incompreensível, afirma, mais de uma vez, que "todas as evidências disponíveis" dessa psicologia (p. ex., p. 169; 180) favorecem a sua leitura nietzschiana.

É com base nessa soberba cientificista que Leiter condena, por exemplo, as psicologias morais de Kant e de Aristóteles ao ostracismo, dado que, segundo a caricatura padrão da nossa época, reforçada por Leiter, essas concepções psicológicas são construídas por filósofos que passam o tempo coçando suas barbas em uma poltrona. "Ponho de lado Aristóteles e os neo-aristotélicos com suas suposições fantasiosas sobre o que significa ser humano: eles têm a vantagem distinta de não considerar, em suas ideias, as evidências empíricas das ciências naturais e humanas sobre como os seres humanos realmente são" (p. 42 , rodapé). ${ }^{4} \mathrm{O}$ próprio Nietzsche, segundo o autor, só teria sido um filósofo parcialmente "especulativo" por necessidade: "A psicologia empírica desenvolveu métodos para testar e confirmar hipóteses que não existiam no século XIX - daí a necessidade de um filósofo de mente naturalista como Nietzsche especular" (p. 10).

Esse retrato se torna especialmente preocupante se considerarmos o grau de fragmentação e divergência de abordagens e métodos existente no âmbito da psicologia acadêmica. Em um trabalho encomendado pela APA (Associação Americana de Psicologia) Koch e Leary (1992) investigaram e apresentaram brevemente o "estado da arte" da psicologia enquanto ciência ao final do seu primeiro século de existência. ${ }^{5}$ A conclusão dos autores é bastante sugestiva

\footnotetext{
4. Digno de nota é o uso das palavras por Leiter ao tratar da postura dos filósofos frente às suas evidências empíricas: "a negligência de Nietzsche na psicologia moral não é mais uma opção para os filósofos que aceitam que a psicologia moral seja fundamentada na psicologia real" (p. 162 - ênfase do autor) 50 marco inicial da psicologia enquanto ramo "independente" é amplamente atribuído à fundação, em 1889, do laboratório de psicologia de Leipzig, por Wilhelm Wundt.
}

192 | Cad. Nietzsche, Guarulhos/Porto Seguro, v.40, n.3, p. 189-213, setembro/dezembro, 2019. 
Quando a ciência é ídolo: um comentário crítico sobre a psicologia...

do problema aqui destacado - que procuro desenvolver na segunda parte do presente texto (a partir de abordagens mais atuais):

Após cem anos de crescimento efervescente, a psicologia alcançou uma condição ao mesmo tempo tão fracionada e tão ramificada a ponto de impedir que duas pessoas concordem com sua 'arquitetura'. Mesmo que uma arquitetura pudesse ser confiavelmente discernida, é duvidoso que todas as suas subestruturas possam ser tratadas em um único estudo com uma chance de conclusão antes do final do terceiro século da psicologia... a psicologia atual parece muito com um quebra-cabeça confuso de "figura oculta" que não contém figura alguma. (Koch e Leary, 1992, p. 2)

O próprio emprego dessa ciência psicológica, no capítulo final do livro (que é dedicado exclusivamente à apresentação das "melhores evidências" que sustentariam a leitura nietzschiana de Leiter), fornece uma ilustração cristalina do problema em questão: Leiter e Knobe apresentam como inconteste (cf. p. 169) o suposto fato de que a psicologia empírica sustenta, contra abordagens aristotélicas e kantianas, que as características herdáveis assumem o papel de traços de caráter estáveis e decisivos na determinação de comportamentos e valores morais do sujeito. Ocorre que, constrangedoramente, a leitura por Knobe e Leiter dessas supostas evidências incontestes diz exatamente o contrário do que outro grande porta-voz do cientificismo psicológico contemporâneo, Gilbert Harman (que é mencionado de passagem por Leiter e Knobe de modo inconsistente, o que abranda artificialmente o antagonismo de suas posições), sustenta como "melhores evidências", isto é, as supostas evidências empíricas de que não há tal coisa como traços de caráter presentes de modo significativo em nossa vida moral.

Ao final, como procuro evidenciar, após uma leitura crítica e detida de cada um desses aspectos, não se sustentam nem a suposição de que há algo como uma ciência psicológica facilmente acessível e dotada de legitimidade consensual (muito menos de capacidade para dizer o que é e o que não é uma reflexão filosófica valiosa),

Cad. Nietzsche, Guarulhos/Porto Seguro, v.40, n.3, p. 189-213, setembro/dezembro, 2019. 193 
Backendorf, J.

nem a suposição de que essa suposta melhor ciência oferece provas claras a respeito das leituras nietzschianas desenvolvidas ao longo do livro de Leiter.

\section{O Nietsche psicólogo de Leiter: pano de fundo conceitual}

Na Leitura de Leiter, Nietzsche é um "naturalista humeano", na medida em que Hume também pretendeu estabelecer "uma teoria geral da natureza humana" nos mesmos moldes com que Newton abordou a filosofia natural (p. 2). Mas Hume, no dizer de Leiter, teria atingido menos do que Nietzsche, "porque suas alegações sobre a natureza humana não são confirmadas por nada semelhante a uma abordagem científica" (algo que Nietzsche, supostamente, teria atingido, conforme Leiter procura provar no capítulo sete). ${ }^{6}$

A argumentação inicial do livro visa a sustentar a leitura que faz Leiter de Nietzsche como antirrealista sobre valores morais, isto é, um Nietzsche que se distancia de qualquer concepção objetiva sobre o que sejam o bem, os valores e/ou os deveres e que se apega, em vez disso, a "fatos psicológicos" subjacentes à nossa vida moral (p. 30). A conclusão de Leiter quanto a este tópico é a de que, "se a melhor explicação de nossos julgamentos morais demanda apenas fatos psicológicos ou fisiológicos sobre nós, e não precisa fazer referência a fatos morais objetivos, então temos motivos para ser céticos quanto à existência de fatos morais objetivos" (p. 30). Esses fatos psicofisiológicos (na medida em que divergem entre as pessoas) explicariam o desacordo "intratável" das diferentes posições dos

\footnotetext{
6 Nas palavras de Leiter, "Hume não se sai tão bem com esse padrão de evidência mais exigente (apesar de se sair melhor do que Kant, com certeza), uma vez que algumas de suas especulações sobre a natureza humana parecem envolver um pensamento positivo sobre as nossas propensões morais: sim, muitas pessoas têm disposições simpáticas em certas circunstâncias, mas também, como Nietzsche costuma enfatizar, elas frequentemente revelam prazer na crueldade" (p. 9).
}

194 | Cad. Nietzsche, Guarulhos/Porto Seguro, v.40, n.3, p. 189-213, setembro/dezembro, 2019. 
Quando a ciência é ídolo: um comentário crítico sobre a psicologia...

filósofos (p. 37). As evidências do que são tais fatos e de como são determinantes é prometida, novamente, para o capítulo sete.

A mesma linha de raciocínio anterior é aplicada também ao problema da existência ou não, no pensamento de Nietzsche, de uma defesa de critérios capazes de sustentar gradações avaliativas que permitiriam afirmar que uma teoria moral (inclusive a sua própria) é melhor do que as demais. Neste caso, portanto, trata-se de discutir sobre quê status têm os valores usados pelo próprio Nietzsche para realizar sua crítica aos valores, por exemplo, da moral cristã. Leiter define seus "adversários" de interpretação como defensores da chamada "leitura privilegiada", segundo a qual Nietzsche veria sua própria teoria como dotada de algum privilégio epistêmico, isto é, como sendo, na pior das hipóteses, "mais justificada" do que as de seus alvos (p. 50). Leiter conclui que as versões que defendem um certo privilégio argumentativo em Nietzsche "estão simplesmente erradas": "a perspectiva avaliativa de Nietzsche ao realizar a reavaliação [dos valores] não goza, de fato, de nenhum privilégio metafísico ou epistêmico em relação a seu objetivo. No fundo, Nietzsche não tem nada a dizer aos leitores que não compartilham seus gostos avaliativos" (p. 65).

Uma das principais teses psicológicas que Leiter promete provar, na parte "empírica" do livro, é exposta detalhadamente no capítulo "Moralities are a Sign-Language of the Affects", em que o autor aborda a tese psicofisiológica segundo a qual a moralidade não é mais do que um produto (um “sintoma", p. 69) da estruturação dos nossos estados psicológicos. Assim como uma dor de garganta é sintoma de uma infecção viral, a moralidade seria sintoma de (e, nesse sentido, causada por) certos movimentos psicológicos dos quais o sujeito não é consciente (p. 70; 76). Atrelado a este tópico estão sobretudo as noções de liberdade e responsabilidade moral. O objetivo do autor é enquadrar a teoria de Nietzsche na tradição sentimentalista, representada por autores como Hume e Herder, 
Backendorf, J.

segundo os quais, nas palavras de Leiter, "a melhor explicação para nossos julgamentos morais se dá em termos de nossas emoções ou respostas afetivas a estados de coisas no mundo, respostas que são, elas próprias, explicáveis em termos de fatos psicológicos sobre o julgador" (p. 67).

Numa fórmula simples, os julgamentos morais, segundo essa concepção, seriam fruto da interação entre dois tipos de resposta afetiva: i) um "afeto (impulso) básico" de inclinação ou aversão por certo estado de coisas e, ii) uma resposta afetiva adicional ("metaafeto") em relação àquele afeto básico (p. 67). Os primeiros, na leitura de Leiter, seriam essencialmente não-cognitivos, enquanto os segundos, na medida em que podem ou não "aderir" aos primeiros, carregam algum componente cognitivo, como a crença (p. 67), e têm, além disso, a participação de aspectos ambientais/culturais introjetados pelo indivíduo (p. 77). Na parte final do capítulo, Leiter antecipa alguns aportes da ciência empírica para sustentar o acerto de Nietzsche. Sobretudo os estudos de Jonathan Haidt, que demonstram que "as pessoas" mantêm suas crenças mesmo quando aceitam já não ter razões para tal (Cf. p. 76), fundamentariam a leitura segundo a qual somos, naquilo em nós que julgamos consciente, meros "títeres" dos nossos afetos inconscientes. Discuto os estudos apresentados por Leiter mais adiante.

A parte mais concretamente psicológica do livro é inaugurada no capítulo cinco, "Nietzsche's Theory of Agency: The Will and Freedom of the Will", que apresenta a leitura de Leiter do "fatalismo" de Nietzsche, cujos termos levariam forçosamente a posicionar Nietzsche como "incompatibilista" quanto à relação entre tal fatalismo e a possibilidade de livre arbítrio. Leiter procura demonstrar que Nietzsche é um "Hard Incompatibilist" que defende, portanto, que "ninguém tem livre arbítrio ou é moralmente responsável" (p. 117). A posição a ser aqui combatida é sobretudo a compatibilista, que, apesar de aceitar um grau forte de determinação causal da vontade, ainda 
Quando a ciência é ídolo: um comentário crítico sobre a psicologia...

assim concebe espaço para o livre arbítrio e para a responsabilidade moral. A análise de Leiter no capítulo passa sobretudo pela observação do que chama de "fenomenologia enganosa da vontade" (p. 120), isto é, a ilusão que temos de que nós mesmos determinamos nosso destino, nossas preferências e nossas ações.

Aqui Leiter se compromete com uma leitura bastante espinhosa segundo a qual "Nietzsche acredita que as possíveis trajetórias da vida de cada indivíduo são fixadas antecipadamente em virtude da natureza do indivíduo" (p. 120), para a qual promete, novamente, evidências a serem apresentadas no capítulo sete. O próprio Nietzsche, nesse sentido, seria um exemplo de produto do destino: na concepção de Leiter, as designações de Nietzsche em Ecce Homo, por exemplo, evidenciam uma personalidade que só poderia ser daquela forma, de modo que os aparentes auto-elogios (ser tão sábio, escrever tão bons livros, etc.) são na verdade alheios a qualquer atribuição de mérito. Nas palavras de Leiter:

Como resultado, a resposta para as perguntas aparentemente autocongratulatórias do "porquê" é mais ou menos a seguinte: "Foi um fato da natureza que eu, Nietzsche, fui um organismo saudável, ou seja, o tipo de criatura que instintivamente faz as coisas certas para facilitar o seu florescimento" [...] Agora temos a resposta para o subtítulo do livro: "como alguém se torna o que é?" A resposta: não fazendo nenhum esforço especial conscientemente direcionado para esse fim, porque alguém se torna o que é necessariamente. (p. 122)

Mas, se é assim, como devemos interpretar os usos frequentes de Nietzsche de conceitos negados (quanto à sua substancialidade) por Leiter, como o de liberdade, autonomia e responsabilidade? $\mathrm{O}$ autor defende, em resposta a essa questão, a hipótese de um uso revisionista desses conceitos por parte de Nietzsche, que os usaria sobretudo com a finalidade de persuadir (dada a força especialmente emotiva de tais conceitos, $c f$. p. 147) e não como referência a entidades metafisicamente reais. Nas palavras do autor: "Nietzsche

Cad. Nietzsche, Guarulhos/Porto Seguro, v.40, n.3, p. 189-213, setembro/dezembro, 2019. 197 
Backendorf, J.

não acredita em liberdade ou responsabilidade; ele não acha que exercemos qualquer controle significativo sobre nossas vidas" (p. 161). Mesmo nos casos em que parece mais difícil negar um espaço para a autonomia, como se vê na descrição do sujeito ideal de Nietzsche, Leiter sugere que não se usem conceitos como liberdade: "afinal, 'liberdade' é um conceito promíscuo" (p. 152).

\section{O Nietsche psicólogo de Leiter: aspectos empíricos}

O capítulo intitulado "The Case for Nietzschean Moral Psychology" representa a concretização do que foi repetidamente prometido por Leiter nas partes anteriores do livro. Elaborado em coautoria com Joshua Knobe, o capítulo apresenta aquilo que os autores concebem como apanhado de evidências empíricas que sustentariam as leituras de Nietzsche feitas por Leiter nos capítulos anteriores. $\mathrm{O}$ capítulo é estruturado de modo a opor a psicologia moral de Nietzsche às psicologias morais de Aristóteles e Kant (sendo a primeira, evidentemente, defendida como vitoriosa). Procedo, agora, a uma exposição mais detida, e crítica, a respeito do que se faz neste capítulo.

A exposição começa com os autores reforçando a tese de que supostamente "até bem recentemente a maioria dos filósofos anglófonos que escrevia sobre psicologia moral tendia a abordar suas perguntas 'da poltrona' e sem considerar as descobertas empíricas pertinentes sobre a psicologia humana"7 (p. 162). Essa desconsideração da realidade empírica seria responsável pelo predomínio, no âmbito

\footnotetext{
7 No livro The Myth of the Intuitive, Deutsch (2015) definiu as abordagens da psicologia experimental, modelo teórico que tem Knobe como um de seus principais representantes, como profundamente problemáticas em sua face "negativa", isto é, no âmbito em que pretendem atacar o fazer tradicional da filosofia como sendo puramente calcado em intuições de poltrona, como se os filósofos de fato não prestassem atenção à adequação empírica de suas abordagens. Essa visão estaria pautada numa distorção grosseira do real valor do trabalho e do método tradicional da filosofia, uma "caracterização que injustamente toma o xphi [filósofo experimental] como curativo - um bálsamo pró-ciência voltado a combater a tendência de simplesmente sentar em uma poltrona e pensar. (Deutsch, 2015, p. 157)
}

198 | Cad. Nietzsche, Guarulhos/Porto Seguro, v.40, n.3, p. 189-213, setembro/dezembro, 2019. 
Quando a ciência é ídolo: um comentário crítico sobre a psicologia...

da psicologia moral, das visões kantiana e aristotélica da agência moral, as quais seriam, como Leiter definiu em passagens anteriores, "fantasiosas" (p. 42). O autor caracteriza a visão aristotélica como comprometida centralmente com a ideia de que o caráter é definido pela educação (em desconsideração a traços genéticos) (pp. 163-5); a visão kantiana como concebendo agentes que se auto impõem, conscientemente, leis morais eficazes em termos motivacionais (165-6); e, por fim, a visão nietzschiana como comprometida com uma forte determinação genética dos traços morais do sujeito: "O que é decisivo [na visão de Nietzsche] não é a educação, os hábitos particulares ou as escolhas conscientes; o que mais importa são os fatos-tipo, isto é, traços psicológicos e fisiológicos herdáveis, que operam abaixo do nível da deliberação consciente" (p. 166).

O mais importante ponto que os autores procuram provar é o que afirma, num primeiro momento, que as pessoas têm sua personalidade pré-determinada por traços biológicos e, adicionalmente, que essa pré-determinação é decisiva na expressão dos comportamentos e valores morais das pessoas (p. 167). As evidências mais importantes, segundo os autores, vêm da genética comportamental, sobretudo das observações de gêmeos e crianças adotadas. Supostamente, um apanhado geral desses estudos, feito por Loehlin, permite estimar que "os fatores genéticos explicam $60 \%$ da variação na extroversão e 50\% na variação no neuroticismo" (p. 167) - sem que Knobe e Leiter se preocupem em explicar exatamente de que maneira. $\mathrm{O}$ primeiro parágrafo da p. 169 é, nesse sentido, especialmente curioso. Após listar uma série sequencial de estudos e percentuais sobre o suposto grau determinação genética do comportamento violento, sem dizer uma única palavra sobre método, os autores concluem: "Esses enormes montantes não podem ser atribuídos de forma plausível a artefatos experimentais ou erros de medição. Claramente, fatores genéticos estão desempenhando um papel substancial na etiologia de certos tipos de violência" (p. 169). 
Backendorf, J.

Um exemplo claro do que há de preocupante na empreitada empírica acrítica de Knobe e Leiter pode ser visto em sua tentativa de comprovar que as características herdáveis assumem o papel de traços estáveis e decisivos na determinação de comportamentos e valores morais do sujeito. Novamente, os autores apresentam como evidências de seu ponto um punhado de estudos pautados em correlações estatísticas não destrinchadas (pp. 172-3). O preocupante aqui é que tese a ser defendida, como representante da "melhor ciência" e sustentada, supostamente, por "todas as evidências disponíveis" (p. 169) diz justamente o contrário do que outros autores, por exemplo Harman (1999; 2000), também famoso porta-voz atual da "melhor ciência" e igualmente contrário à visão aristotélica do caráter, defende. Knobe e Leiter, em alguma medida, estão cientes disso, e sugerem que, apesar das aparências, não haveria contradição entre suas abordagens, dado que o ponto defendido por Harman seria a necessidade de se poder prever, se houvessem traços de caráter estáveis, "comportamentos específicos" (p. 171), enquanto a tese de Nietzsche defenderia que esses traços de caráter determinam a "estrutura de uma vida, e não casos particulares isolados de conduta" (p. 171 - ênfase minha).

Ora, uma simples leitura dos textos de Harman evidencia a distorção provocada aqui por Knobe e Leiter, algo que, intencionalmente ou não, acaba por dirimir artificialmente o conflito entre suas abordagens. $\mathrm{O}$ próprio título de um dos mais representativos textos de Harman sobre o assunto é justamente The Nonexistence of Character Traits (2000); neste e em outros artigos (1999, p. ex.), o autor defende com todas as letras (e com o mesma energética postura pró psicologia empírica) que as melhores evidências, que os filósofos de poltrona (neste caso, especificamente, os aristotélicos) supostamente insistem em ignorar (1999, p. 316), demonstram que "não há base empírica para a existência de traços de caráter" (1999, p. 316). Diferentemente do que sugerem Knobe e Leiter, no entanto, os 
Quando a ciência é ídolo: um comentário crítico sobre a psicologia...

traços de caráter são definidos por Harman como incluindo "virtudes e vícios como coragem, covardia, honestidade, maldade, orientação amistosa e não amistosa...", e têm como característica distintiva o fato de serem “disposições estáveis de longo prazo" (1999, pp. 3167). Ou seja, estão muito distantes de "casos particulares isolados de conduta" sugeridos por Knobe e Leiter (p. 171) como sendo tudo o que importa na tese de Harman.

Uma esclarecedora passagem, citada por Harman em reforço a seu argumento, toca no aspecto central da presente discussão, sugerindo que mesmo naqueles aspectos em que aparentemente há uma estabilidade de traços de caráter, isso se deve às condicionantes do ambiente, e não a aspectos intrínsecos ao agente: “Assim, clérigos e criminosos raramente enfrentam um conjunto idêntico ou equivalente de desafios situacionais. Em vez disso, eles se colocam e são colocados pelos outros em situações que diferem precisamente de maneiras que induzem o clérigo a aparentar, agir, sentir e pensar de maneira consistente como o clero e que induzem os criminosos a aparentar, agir, sentir e pensar como os criminosos" (Nisbett \& Ross, apud Harman, 1999, p. 320 - ênfase minha). ${ }^{8}$

Outra tese que Leiter e Knobe procuram "provar", dessa vez contra Kant, é a de que a consciência (ou a racionalidade) é inoperante em nossa vida moral. É curioso, nesse sentido, retomar uma argumentação prévia a respeito do assunto nos capítulos anteriores, algo útil para evidenciar uso indiscriminado das palavras por parte de Leiter. Ao expor o problema, no capítulo três, o autor cita uma passagem em que Nietzsche, em Aurora, afirma que "somos todos

8 Adicionalmente, Harman cita novamente os estudos de Nisbett e Ross, cujos resultados são lidos de modo diametralmente oposto aos defendidos por Knobe e Leiter; aqui temos mais uma evidência do exagero de se afirmar que "todas as evidências" da "melhor ciência" suportam a tese dos autores: "Resumindo vários estudos, Ross e Nisbett (1991: 95) relatam que a 'correlação média entre diferentes medidas comportamentais projetadas para explorar o mesmo traço de personalidade (por exemplo, impulsividade, honestidade, dependência ou similar) estava tipicamente na faixa entre 0,10 e 0,20, e muitas vezes foi ainda mais baixa'. Essas são correlações muito baixas, abaixo do nível que as pessoas podem detectar." (Nisbett \& Ross, apud Harman, 1999, p. 326 - ênfase minha).

Cad. Nietzsche, Guarulhos/Porto Seguro, v.40, n.3, p. 189-213, setembro/dezembro, 2019. | 201 
Backendorf, J.

irracionais" e, apesar de dizer que se trata de "uma afirmação bem fundamentada pela recente literatura empírica" (p. 76), o autor descreve os estudos de Haidt como demonstrando que "as pessoas frequentemente" agem de tal modo irracional. Ora, há uma diferença abissal quando se sabe que o que está em jogo aqui é a tese kantiana da autonomia da vontade, entre essas duas afirmações. Além do mais, discutir quem são essas "pessoas" estudadas por Haidt (lembremos que Kant nunca sugeriu que sua teoria da agência fosse amplamente compartilhada) e questionar as implicações do fato de que o próprio Haidt assume "exceções" a essa regra é algo que parece não importar na empreitada de Leiter. ${ }^{9}$

Não menos problemática na discussão de Leiter e Knobe sobre essa questão são os estudos, citados pelos autores como "influentes" (p. 175), realizados na primeira metade do século passado pelo psicólogo social LaPiere. LaPiere, segundo o relato de Leiter e Knobe, visitou, acompanhado de um casal de chineses, mais de 250 estabelecimentos (hotéis e restaurantes) em uma região de forte preconceito contra chineses. Apenas um desses estabelecimentos recusou atendimento. Posteriormente, LaPiere enviou uma carta a todos os estabelecimentos perguntando o seguinte: "você aceitaria pessoas de raça chinesa como clientes em seu restaurante"? Dos respondentes, dizem Leiter e Knobe, mais de 90\% responderam negativamente, o que sugere, na conclusão do autor, que de fato há uma incongruência entre a atitude consciente e o comportamento real. Ora, algumas ressalvas são fundamentais aqui. Primeiro, o que Leiter e Knobe não nos informam é que menos da metade de todos os estabelecimentos perguntados de fato respondeu à carta enviada

\footnotetext{
9 Haidt afirma, por exemplo, que algumas pessoas muito treinadas (ou muitas pessoas em momentos raros) podem agir motivadas pelas razões, sobrepondo-se mesmo a fortes intuições. Especialmente os filósofos, diz o autor, teriam a capacidade de "raciocinar bem" (Cf. Haidt, 2001, p. 819). Ora, se isso é verdade, então poderíamos devolver o desafio a Leiter: trata-se, afinal, de uma questão de formação/treinamento? Um estudo melhor conduzido, feito com pessoas selecionadas, poderia mostrar resultados opostos à tese aqui defendida como amplamente confirmada empiricamente?
}

202 | Cad. Nietzsche, Guarulhos/Porto Seguro, v.40, n.3, p. 189-213, setembro/dezembro, 2019. 
Quando a ciência é ídolo: um comentário crítico sobre a psicologia...

por LaPiere ( $c f$. LaPiere, 1934, pp. 233-4), algo que pode evidenciar justamente que a maior parte não tem uma atitude contrária aos chineses. Além disso, mesmo os que responderam afirmando que não atenderiam precisam ter sua resposta contextualizada: uma resposta dada a uma carta com conteúdo estereotipado, enviada por alguém distante e desconhecido, realmente permite captar o que as pessoas realmente pensam conscientemente? Poderia ser o caso, por exemplo, de que esses estabelecimentos estavam apenas preocupados com o andamento dos negócios, querendo, por um lado, manter sua "respeitabilidade" pública (afinal, a região em que se localizavam era fortemente preconceituosa em relação a chineses), mas, por outro, fazendo pouco caso, na prática, da presença de tais clientes, dado que estavam movimentando o local. Pode ser o caso, além disso, de que a aparência do casal chinês não era claramente estereotipada. O próprio fato de estarem acompanhados de um não-chinês pode ter feito toda a diferença. Seja como for, é deveras curioso como um estudo tão pobre metodologicamente pode ser incluído sem qualquer ressalva crítica no rol do que Leiter chama "ciência que funciona" ${ }^{10}$

\section{Quando "melhores evidências" significa hifenizações estatisticamente generalizadas}

O fato de que um aspecto central da "melhor ciência" de Knobe e Leiter está em direta oposição à "melhor ciência" de Harman, somado aos problemas metodológicos e de interpretação que apontei em relação aos demais estudos, representa uma importante ilustração do problema que venho destacando desde o início da presente exposição. Vale lembrar que Leiter concebeu Nietzsche como um

10 Não obstante isso, é importante salientar, mais uma vez, contra a suposição de consenso afirmada por Leiter, que há diversos estudos (que eu cito apenas por este motivo específico), defendendo a tese de que as atitudes refletidas das pessoas são decisivas na determinação do seu comportamento (Cf., p. ex., Stocké, 2006; Ajzen e Fishbein, 1980; Eagly e Chaiken, 1993; Chiou, Huang e Chuang; 2005 - todos esses estudos são apresentados em Torres e Neiva, 2011, pp.181-4)

Cad. Nietzsche, Guarulhos/Porto Seguro, v.40, n.3, p. 189-213, setembro/dezembro, 2019. $\mid 203$ 
Backendorf, J.

naturalista, definiu o naturalismo como um estar vinculado aos métodos das "ciências que funcionam", e construiu parte significativa do seu empreendimento supostamente demostrando que de fato essas ciências, em sua versão atual, sustentam as visões psicológicas de Nietzsche. Mais impressionantemente ainda, defendeu que essa ciência, enquanto avalista do naturalismo, detém primazia em relação à própria sabedoria filosófica na determinação do que é um raciocínio valioso. $\mathrm{O}$ que em nenhum momento foi feito, em todo o livro, é questionar a real plausibilidade de se falar nesses termos, sem qualquer problematização, em relação à psicologia.

A verdade é que essa suposta facilidade em evocar a "ciência que funciona" e "as melhores evidências", em psicologia, só pode ser atingida com uma forte negligência de toda a problemática histórica, tão viva hoje quanto em qualquer momento, em relação à colocação da psicologia no rol das ciências, problema que começa já pela indefinição permanente de qual é, exatamente, seu objeto de estudo. A assim chamada "psicologia humanista", cujas origens remetem a Fromm, Horney e sobretudo Maslow (autores definidos por Swanton (2005) como de orientação nietzschiana) ${ }^{11}$, é um exemplo disso: desde meados do século passado, atua, no âmbito acadêmico, afirmando uma postura radicalmente contrária ao fazer psicológico mainstream, denunciando sobretudo "a ambição implacável da psicologia por compartimentar - por fragmentar e subdividir o conhecimento", sugerindo a conclusão segundo a qual graças a essa "pressa de encontrar mecanismos, abstrações e fórmulas, estamos negligenciando

\footnotetext{
11 A seguinte passagem, que sintetiza a postura básica compartilhada pelos autores humanistas, talvez evidencie que, pelo menos em parte, a associação dessa vertente psicológica com o filosofar crítico de Nietzsche não se dê sem razão: "Sem dúvida, parece cada vez mais evidente que aquilo a que chamamos "normal" em psicopatologia é, realmente, uma psicopatologia do indivíduo comum, tão vulgar e tão generalizada que, habitualmente, nem a notamos. O estudo [...] da pessoa autêntica e da existência autêntica ajuda a colocar esse artificialismo geral, essa existência baseada em ilusões e no medo, sob uma luz crua e forte que revela claramente a sua natureza doentia, ainda que amplamente compartilhada" (Maslow, 1968, p. 37)
}

204 | Cad. Nietzsche, Guarulhos/Porto Seguro, v.40, n.3, p. 189-213, setembro/dezembro, 2019. 
Quando a ciência é ídolo: um comentário crítico sobre a psicologia...

o ser a quem essas modalidades se aplicam" (Schneider et al., 2015, xvii).

Mas a crítica à psicologia mainstream não se restringe aos humanistas. Autores como Barresi \& Martin (2011), num apanhado geral dos trabalhos psicológicos sobre a agência humana, concluíram (fazendo eco ao caso que expus na introdução do presente texto) que existe, dentro da psicologia, uma catastrófica fragmentação de abordagens, cada uma com pressupostos que, via de regra, não se comunicam com as demais, fenômeno que os autores descrevem como "hifenização" dos estudos psicológicos. Ao tratar do mesmo assunto, Leary \& Tangney (2012) apresentam uma tabela expondo os impressionantes modos pelos quais o self é abordado em recortes da psicologia especializada. A lista conta com mais de 60 conceitos "hifenizados" (p. ex.: auto-conhecimento, auto-estima, auto-confiança, auto-controle, auto-aceitação, auto-realização, etc. - cf. Leary \& Tangney, 2012, pp. 9-10). Lembremos: a principal tarefa da psicologia moral, na visão de Leiter, é apresentar uma concepção empiricamente sustentada do que é ser um agente humano. Pode uma tal psicologia oferecer algo próximo de uma descrição fidedigna da complexidade humana? Nas palavras de Barresi \& Martin: "os pesquisadores perderam contato com qualquer coisa que mereça ser chamada de um self. [...] no final do século XX o self unificado tinha morrido a morte, se não de mil qualificações, a das mil hifenizações" (2011, pp. 50-1).

Essa realidade de fragmentação e desconexão entre estudos diversos não se dá sem motivo. Em um trabalho recente, Smedslund (2015), que descreve a psicologia atual como "quase exclusivamente pautada em generalizações estatísticas"12 apontou

12 "Os resultados da psicologia moderna consistem quase exclusivamente em dados médios de muitos indivíduos desconhecidos pelo pesquisador. No entanto, não se pode fazer inferências válidas das médias para os indivíduos, e, afinal, a psicologia é sobre indivíduos [...]. Portanto, existem muitos tipos de fenômenos psicológicos inacessíveis ao pesquisador atual. $O$ que é estudado é frequentemente do tipo "estímulo-resposta", isto é, uma sequência linear, da entrada à saída. Observa-se como

Cad. Nietzsche, Guarulhos/Porto Seguro, v.40, n.3, p. 189-213, setembro/dezembro, 2019. $\mid 205$ 
Backendorf, J.

para a falha estrutural de se pretender uma psicologia feita de medições semelhantes às das ciências naturais, sobretudo devido à impossibilidade de mensurar o real conteúdo dos estados psíquicos e dos traços de personalidade de sujeitos humanos. E mesmo que esses aspectos pudessem ser minimamente compreendidos, acrescenta o autor, ainda assim haveria o problema insanável da "mutabilidade" dos estados psíquicos humanos ao longo do tempo (inclusive como reflexo das próprias pesquisas psicológicas), algo que impede a obtenção de dados consistentes. De fato, num movimento conjunto por avaliar o grau de replicabilidade dos estudos psicológicos, feito por 270 colaboradores, chegou-se à conclusão de que, mesmo dentro de uma escala temporal relativamente curta, apenas algo em torno de $39 \%$ dos estudos replicados (estudos, é importante enfatizar, via de regra calcados em algum dos recortes "hifenizados" acima apontados) apresentavam resultados equivalentes aos sugeridos pelas pesquisas originais. (Cf. Nosek et al., 2015).

Em seu recém lançado trabalho sobre o assunto, Lamiell (2019) não apenas reforça a tese de que "os métodos estatísticos agregados de investigação dominam completamente a pesquisa psicológica moderna", mas, mais importante, que isso é um problema para o qual toda a institucionalização científica permanece blindada, fingindo se tratar de uma realidade inexistente e tornando a prática psicológica incorrigível (Lamiell, 2019, p. xii). Na síntese do autor:

[...] o pensamento predominante na psicologia científica tem sido dominado por práticas interpretativas que são inválidas, mas que também foram impenetráveis a críticas ponderadas a essas práticas. Para colocar as coisas de maneira sucinta, a preocupação é que, além de ser conceitualmente equivocado, o campo também tem sido, pelo menos até agora, efetivamente incorrigível. Para uma pretensa disciplina científica, essa incorrigibilidade é terrivelmente doentia, e isso por si só seria motivo suficiente para denunciar

\footnotetext{
as pessoas, em média, respondem a instrumentos de pesquisa e condições experimentais. Essa metodologia deixa de fora informações sobre áreas centrais do que é essencialmente humano..." (Smedslund, 2015, p. 193)
}

206 | Cad. Nietzsche, Guarulhos/Porto Seguro, v.40, n.3, p. 189-213, setembro/dezembro, 2019. 
Quando a ciência é ídolo: um comentário crítico sobre a psicologia...

novamente à comunidade acadêmica os problemas conceituais fundamentais que já se incorporaram ao próprio tecido epistemológico da psicologia. Em seu estado profundamente adoecido, a psicologia está proferindo alegações de conhecimento que são injustificadas [...] (Lamiell, 2019, pp. xi-xii) ${ }^{13}$

\section{É importante salientar que a questão aqui não é meramente} interpretativa. De fato, as principais abordagens da psicologia tida como dominante, como evidencia a própria exposição de Leiter e Knobe, são pautadas num paradigma predominantemente estatístico que tenta imitar as ciências naturais. Os custos impagáveis disso, para uma leitura nietzschiana, deveriam ser evidentes. Trata-se, dentre diversos problemas, de uma psicologia da "regra", que simplesmente ignora e, consequentemente, bane a "exceção". ${ }^{14}$ Uma psicologia bastante útil e servil ao que Erich Fromm (2008), no que poderíamos chamar de uma leitura verdadeiramente nietzschiana, definiu como "patologia da normalidade", isto é, uma espécie de "validação consensual" (Fromm 2008, p. 14) do que são as capacidades e qualidades humanas ancorada pela "objetividade" estatística - que, no entanto, não é mais do que expressão do "comum", "regular", não importando quão viciosa e desafortunada for a situação que gera

$13 \mathrm{Em}$ um estudo em que analisa, a partir do mais famosos experimentos da psicologia social (p. ex., os experimentos de Zimbardo feito em prisões, o teste de autoridade de Milgram e o experimento de conformidade de Asch), como os vieses e distorções morais e sociais têm espaço aberto para influenciar os resultados dessas investigações (na leitura do autor, isso se daria sobretudo porque a psicologia não é alimentada por "fatos duros" como as demais ciências naturais e, por consequência, falha em estabelecer métodos de investigação que ao mesmo tempo sejam minimamente sólidos e não percam de vista a complexidade de seu objeto), Brannigan sustenta o mesmo: "A psicologia social falhou como ciência, não porque cometeu erros, mas porque parece incapaz de reconhecê-los como tais. $O$ que é alarmante é que os devotos da psicologia social parecem não atribuir muita gravidade a essa situação, ou não sabem o que fazer a respeito" (Brannigan, 2017, p. 142)

14 Veja-se, como exemplo emblemático disso, os diversos estudos "situacionistas", sem exceção pautados no modo como a maioria estatística dos sujeitos age em situações artificialmente elaboradas pelos investigadores (para uma exposição introdutória, ver Miller, 2003). Além da falha em captar aspectos relevantes do que realmente constitui a personalidade pessoal, esses estudos, mesmo se obtivessem sucesso nessa empreitada, nos transmitiriam apenas uma imagem da personalidade estatisticamente majoritária.

Cad. Nietzsche, Guarulhos/Porto Seguro, v.40, n.3, p. 189-213, setembro/dezembro, 2019. $\mid 207$ 
essa postura majoritária ${ }^{15}$ - uma verdadeira ciência de rebanho que, nas defesas enérgicas e acríticas dos nossos porta-vozes da ciência psicológica "que funciona" como orientadora balizadora da filosofia moral, acaba por se caracterizar como uma moralidade de rebanho atestada cientificamente.

\section{Considerações Finais}

Poucas vezes, em tempos recentes, a sede por objetividade nas ciências psíquicas ganhou traços tão explícitos e salientes como na entrevista do neurocientista Ivan Izquierdo, em que o aclamado investigador afirmou: “a psicanálise foi superada pelos estudos em neurociência, é coisa de quando não tínhamos condições de fazer testes, ver o que acontecia no cérebro. Hoje a pessoa vai me falar em inconsciente? Onde fica? Sou cientista, não posso acreditar em algo só porque é interessante." 16 A postura de Izquierdo faz eco a

15 Nas palavras de Fromm: "Ingenuamente, assume-se que o fato de a maioria das pessoas compartilhar certas ideias ou sentimentos comprova a validade dessas ideias e sentimentos. Nada está mais longe da verdade. [...] $\mathrm{O}$ fato de milhões de pessoas compartilharem os mesmos vícios não torna esses vícios virtudes, o fato de compartilharem tantos erros não faz com que os erros sejam verdades, e o fato de milhões de pessoas compartilharem as mesmas formas de patologia mental não torna essas pessoas sãs" (Fromm, 2008, pp. 14-5)

16Entrevista concedida ao jornal Folha de São Paulo, acessível pelo link https://wwwl.folha.uol. com.br/equilibrioesaude/2016/06/1783036-estudos-de-neurociencia-superaram-a-psicanalise-dizpesquisador-brasileiro.shtml

É especialmente interessante ler o que diz Izquierdo à luz da seguinte passagem, que trata do modo como a psicologia passou de um ceticismo filosófico muito sério quanto às suas reais possibilidades científicas a uma repentina e fácil defesa cientificista: "Nesse contexto, como é que a psicologia contemporânea recebe tão prontamente status científico? As objeções e reservas de Kant, Mill, Wundt e outros foram respondidas? Foi demonstrado que estavam errados? Claramente não. Em vez disso, o que aconteceu foi que os psicólogos descartaram justamente os problemas e questões que tradicionalmente excluíam a psicologia do panteão das ciências, ao mesmo tempo em que adotaram uma classe diferente de problemas adequados aos métodos das ciências desenvolvidas. A estratégia alguns podem chamar isso de manobra - foi essa. Descobre-se que as questões legadas pela história são simplesmente intratáveis quando abordadas com as ferramentas da ciência experimental. Mas, ao se adotar apenas essas ferramentas, passa-se a estudar uma série de problemas subsidiários (ou não-problemas) adaptados aos métodos agora oficiais. Então, depois de anos de sucesso em resolvêlos, declara-se que os problemas originais não eram problemas, pois, se fossem, os métodos oficiais os teriam resolvido também!" (Robinson, 1992, p. 62 - ênfase minha)

208 | Cad. Nietzsche, Guarulhos/Porto Seguro, v.40, n.3, p. 189-213, setembro/dezembro, 2019. 
Quando a ciência é ídolo: um comentário crítico sobre a psicologia...

uma tendência não tão recente de buscar uma completa redução do humano aos procedimentos laboratoriais. Essa mesma aspiração por objetividade e por merecer o carimbo de ciência tem dominado a psicologia que predomina nos espaços acadêmicos. Como procurei evidenciar na parte final da presente reflexão, essa tendência é responsável, em uma de suas facetas principais, por uma ampla e intratável diversidade de abordagens fragmentadas, distorções estatísticas e conclusões arbitrárias, situação em que se pode dizer, sem exagero, que o método constantemente mutila seu objeto de estudo.

Qualquer um, diante de um empreendimento de psicologia moral concebido como de base e inspiração nietzschiana, esperaria uma abordagem aguçadamente crítica em relação às nuances e aos problemas profundos que não apenas esse, mas diversos outros aspectos atrelados à imagem humana, de ciência e de psicologia moral, geradas e alimentadas em tal contexto. Infelizmente, quem se depara com a construção de Leiter encontra justamente o oposto: uma defesa acrítica de um suposto consenso metodológico das ciências psíquicas, que não apenas são tomadas apressadamente como fontes das "melhores evidências", mas, enquanto avalistas do naturalismo, são posicionadas também como autoridade de primeira ordem na determinação do que é e do que não é uma reflexão filosófica válida. A divergência explícita, que procurei evidenciar, entre as "melhores evidências" de Leiter e Knobe e as "melhores evidências" de Harman torna transparente a raiz do problema de tal postura.

O aparente desdém de Leiter em relação ao valor do trabalho filosófico, que se manifesta repetidamente em passagens como "filósofos precisam encarar a possibilidade de que grande parte de sua atividade e sua disputa aparentemente intratável se deva ao fato de ser uma atividade intelectual sem nenhum conteúdo cognitivo real" (p. 48), aliado a essa fé num naturalismo comprometido acriticamente com as ciências naturais e humanas "que funcionam" ("os naturalistas 
Backendorf, J.

negam que exista algo chamado 'raciocínio filosófico’ que se afaste dos tipos de raciocínio que funcionam nas várias ciências naturais e humanas" (p. 106)), transmitem a forte impressão de que talvez, para Leiter, Deus ainda esteja vivo ${ }^{17}$ - e vestindo jaleco branco, com planilhas estatísticas nas mãos.

17 Aqui faço uso da ironia que o próprio autor dirige a diversos de seus rivais de interpretação de Nietzsche $-c f$. , p. ex., p. 13

210 | Cad. Nietzsche, Guarulhos/Porto Seguro, v.40, n.3, p. 189-213, setembro/dezembro, 2019. 
Quando a ciência é ídolo: um comentário crítico sobre a psicologia...

\section{When Science is Idol: A Critical Commentary on Leiter’s Nietzschean Moral Psychology}

Abstract: This article has a very specific purpose: to highlight the problems of Brian Leiter's uncritical treatment of psychology in his recent Moral Psychology with Nietzsche (2019). The author includes, without engaging in any methodological discussion, psychology in the list of what he calls "successful sciences" (i) as certifiers of Nietzschean m-naturalism; ii) as endowed with primacy over philosophy itself in determining what is meaningful "philosophical reasoning"; iii) as providing a broad and uncontested body of evidence that Nietzsche's moral psychology "is right" in profoundly complex theses. My expository strategy is to map, initially, the path taken by Leiter in the conceptual construction of his m-naturalism, and, later, to show that there is nothing in contemporary empirical psychology that legitimizes Leiter's characterization.

Keywords: Leiter, Nietzsche, Naturalism, Science, Psychology.

\section{Referências}

BARRESI, John. MARTIN, Raymond. History as Prologue: Western Theories of the Self. In: Gallagher, S. The Oxford Handbook of The Self. New York: Oxford University Press, 2011, pp. 33-56

BRANNIGAN, Augustine. The Rise and Fall of Social Psychology: The Use and Misuse of the Experimental Method. New York: Routledge, 2017

COX, Cristoph. Nietzsche: Naturalism and Interpretation. Berkeley: University of California Press, 1999

DEUTSCH, Max. The Myth of the Intuitive: Experimental Philosophy and Philosophical Method. Cambridge: MIT Press, 2015

FROMM, Erich. The Sane Society. London and New York: Routledge Classics, 2008

GIACOIA JR., Oswaldo. Nietzsche como Psicólogo. São Leopoldo: Editora Unisinos, 2001

HAIDT, Jonathan. The Emotional Dog and Its Rational Tail: A Social Intuitionist Approach to Moral Judgment. Psychological Review. Vol. 108. No. 4, 814834, 2001

Cad. Nietzsche, Guarulhos/Porto Seguro, v.40, n.3, p. 189-213, setembro/dezembro, 2019. 211 
Backendorf, J.

HARMAN, Gilbert. Moral Philosophy Meets Social Psychology: Virtue Ethics and the Fundamental Attribution Error. Proceedings of the Aristotelian Society, New Series, Vol. 99 (1999), pp. 315-331

. The Nonexistence of Character Traits. Proceedings of the Aristotelian Society, Vol. 100 (2000), pp. 223-226

KOCH, Sigmund; LEARY, David E. (Edits.) A Century of Psychology as Science. Washington: American Psychological Association, 1992

LAMIELL, James T. Psychology's Misuse of Statistics and Persistent Dismissal of its Critics. Cham: Palgrave Macmillan, 2019

LAPIERE, Richard T. Attitudes vs. Actions. Social Forces, Vol. 13, No. 2, pp. 230-237, 1934

LEARY, Mark R.; TANGNEY, June P. (Edits.). Handbook of Self and Identity. New York: The Guilford Press, 2012

LEITER, Brian. Moral Psychology with Nietzsche. New York: Oxford University Press, 2019

MASLOW, Abraham. Introdução à Psicologia do Ser. Rio de Janeiro: Eldorado, 1968

MILLER, Christian B. Social Psychology and Virtue Ethics. The Journal of Ethics. 7: 365-392, 2003

NIETZSCHE, F. Sämtliche Werke. Kritische Studienausgabe (= KSA: 15 vols.). Hrsg. von G. Colli und M. Montinari. Berlin/New York: de Gruyter, 1988. . Além do bem e do mal. Trad. de Paulo César de Souza. São Paulo: Cia. das Letras, 1999. . Ecce homo. Trad. Paulo César de Souza. São Paulo: Companhia das Letras, 2008.

. Segunda Consideração Intempestiva. Trad. de Marco Antônio Casanova. Rio de Janeiro: Relume Dumará, 2003.

NOSEK, Brian A., et al. (Open Science Collaboration). Estimating the Reproducibility of Psychological Science. Science. 349(6251), 2015 
Quando a ciência é ídolo: um comentário crítico sobre a psicologia...

ROBINSON, Daniel N. Science, Psychology, and Explanation: Synonyms or Antonyms? In: KOCH, Sigmund; LEARY, David E. (Edits.) A Century of Psychology as Science. Washington: American Psychological Association, 1992

SMEDSLUND, Jan. Why Psychology Cannot be an Empirical Science. Integrative Psychological Behavioral Science, 50(2), 2015, pp. 185-195

SCHNEIDER, Kirk J; PIERSON, J. Fraser. BUGENTAL, James F. T. (Edits.) The Handbook of Humanistic Psychology: Theory, Research, and Practice. Los Angeles: Sage Publications, 2015

SWANTON, Christine. Virtue Ethics: A Pluralistic View. New York: Oxford University Press, 2005

TORRES, Cláudio V.; NEIVA, Elaine R. Psicologia Social. São Paulo: Artmed, 2011

Recebido em 16/10/2019

Aceito em 16/11/2019

Cad. Nietzsche, Guarulhos/Porto Seguro, v.40, n.3, p. 189-213, setembro/dezembro, 2019. | 213 